\title{
Helicobacter pylori CagA seropositivity in adult Bangladeshi patients with peptic ulcer and erosion
}

\author{
Fahmida Rahman ${ }^{1}$, Khandaker Shadia ${ }^{1}$, Salma Khatun ${ }^{1}$, Mafruha Mahmud ${ }^{2 a}$, Indrajit Kumar Dutta ${ }^{3}$, \\ Jalaluddin Ashraful Haq ${ }^{{ }^{*}}$ \\ ${ }^{1}$ Department of Microbiology, Ibrahim Medical College, Dhaka; ${ }^{2 a}$ School of Public Health and Community \\ Medicine, University of New South Wales (UNSW), Australia; ${ }^{3}$ Department of Gastroenterology, \\ Hepatobiliary and Pancreatic Diseases, Bangladesh Institute of Research and Rehabilitation in Diabetes, \\ Endocrine and Metabolic Disorders (BIRDEM), Dhaka
}

\begin{abstract}
Background: CagA IgG antibody in sera might indicate presence of virulent Helicobacter pylori in patients with peptic ulcer disease. Present study was performed to find out the prevalence of CagA IgG antibody in patients with peptic ulcer/erosion.

Methods: Any case that had peptic ulcer/erosion, plus positive for rapid urease test (RUT) or $H$. pylori stool antigen (HpSAg) or serum anti-H. pylori IgG/IgA were included in the study and named as $H$. pylori positive case. $H$. pylori positive cases were tested for CagA IgG antibody. Anti-H. pylori IgG, IgA and CagA IgG antibodies were determined by enzyme-linked immunosorbent assay (ELISA) and stool antigen by rapid immunochromatographic test (ICT). Urease production in biopsy sample was detected by RUT.

Results: Total $86 \mathrm{H}$. pylori positive patients were included in the study. Out of 86 patients, CagA IgG was positive in 34 (39.5\%; $95 \% \mathrm{Cl}: 0.30,0.50)$ cases. CagA seropositivity rate in ulcer and erosion cases were $58.8 \%(95 \% \mathrm{Cl}: 0.36,0.78)$ and $34.8 \%(95 \% \mathrm{Cl}: 0.25,0.47)$ respectively. $H$. pylori stool antigen and IgA antibodies were positive in all (100\%) CagA antibody positive ulcer cases while the rates were significantly less among the CagA antibody negative cases $(42.8 \%$ and $28.6 \% ; p<0.05)$. However, in CagA antibody positive erosion cases, the rates were not significantly different from CagA antibody negative cases.
\end{abstract}

Conclusion: The study has demonstrated that the CagA positive strain is less prevalent in erosion than ulcer cases.

IMC J Med Sci 2020; 14(1): 006. EPub date: 05 April 2020

\section{Introduction}

Helicobacter pylori infects about half of the world population, but only a small percentage develops clinical diseases. Outcome of infection is determined by the host factors, environment, virulence and genetic heterogeneity of $H$. pylori [1]. Now-a-days several virulence associated genes have been identified in the genome of $H$. pylori $[2,3]$. Vacuolating cytotoxin (vacA) gene is present in all $H$. pylori strains and encodes a vacuolating cytotoxin. Cytotoxin associated gene $(\operatorname{cag} A)$ is not present in all $H$ pylori strains, and is considered as a marker for the presence of a pathogenicity island of $35-40 \mathrm{kbp}$ in the bacterial genome. This island contains a number of genes, whose products are associated with increased pathogenicity of $H$. pylori. It can induce local epithelial cells to release cytokines namely interleukin-8 and 6 and tumor necrosis factor- $\alpha$ (TNF- $\alpha$ ). This may be the reason why cagA positive strains are more prevalent in

*Correspondence: J. Ashraful Haq, Department of Microbiology, Ibrahim Medical College, 1/A Ibrahim Sarani, Segunbagicha, Dhaka 1000, Bangladesh. Email: jahaq54@yahoo.com ; 2a: present address 
patients with peptic ulcers compared with patients with gastritis only [4-6]. Study has reported that the occurrence of CagA positive $H$. pylori is higher among peptic ulcer disease $(93.4 \%)$ than functional dyspepsia (64.6\%) [7]. In the present study, $H$. pylori CagA seropositivity has been evaluated in adult patients with peptic ulcer and erosion.

\section{Materials and methods}

Study population and case definition: Adult patients with dyspeptic symptoms attending the BIRDEM General Hospital for diagnostic endoscopy were enrolled in the study and screened for peptic ulcer/erosion, urease production in biopsy samples, $H$. pylori stool antigen and serum $\operatorname{lgG} / \lg A$. Any case that had peptic ulcer/erosion and positive for rapid urease test (RUT) or $H$. pylori stool antigen or serum anti- $H$. pylori IgG/IgA was included in the study and designated as $H$. pylori positive case. Patients treated with any antibiotics, colloidal bismuth compounds, proton pump inhibitors (PPI) or $\mathrm{H}_{2}$ blocker within the last four weeks were excluded from the study. Patients were diagnosed as ulcer or erosion by endoscopy. The study was approved by the Institutional Review Board and written informed consent was obtained from all cases. The study period was from July 2012 to February 2014.

Sample collection: Gastric biopsy specimen(s) was obtained during endoscopy for detection of $\mathrm{H}$. pylori infection by rapid urease test (RUT). Stool (20-30 gm) and blood $(2.5 \mathrm{ml})$ samples were collected from each patient. Stool samples were tested for $H$. pylori antigen within 6 hours of collection. Blood was used for the detection of $H$. pylori IgG and IgA and CagA IgG antibodies. Serum was separated and stored at $-20^{\circ} \mathrm{C}$ until used.

H. pylori stool antigen assay: H. pylori stool antigen was detected by ABON one step $H$. pylori antigen ICT test device (Inverness Medical Innovation Hong Kong Limited). The test was performed as per instruction of the manufacturer. About $50 \mathrm{mg}$ of feces was taken from three different sites of collected stool and mixed with extraction solution. The tube was shaken vigorously using vortex mixer and then centrifuged for 5 minutes at $4000 \mathrm{rpm}$.
The supernatant was used for the assay. Two drops of extracted stool sample was added to the sample well of the test kit. The result was read 10 minutes after dispensing the sample. A test was considered positive when a purple-pink line (test line) appeared in addition to the control line and was considered negative when only the control line appeared. Lack of control line indicated invalid result.

H. pylori IgG, IgA and CagA IgG detection by ELISA: Serum samples were tested for the presence of anti-H. pylori IgG, IgA and CagA IgG antibodies by ELISA kit from DRG International Inc. USA. The test was performed and interpreted according to the manufacturer's instruction.

Rapid urease test (RUT): The biopsy specimen was inoculated in the rapid urease test media. The test was considered positive if the colour of the medium changed from yellow to pink after 4 hours of incubation at $37^{\circ} \mathrm{C}$.

\section{Results}

A total of $86 \mathrm{H}$. pylori positive cases with either peptic ulcer or erosion were included in the study. Of 86 patients, 17 (19.8\%) and 69 (80.2\%) had peptic ulcer and erosion respectively. Out of 86 cases, $H$. pylori CagA antibody was present in 34 (39.5\%) cases (Table-1). Among ulcer, the CagA antibody was positive in $58.8 \%(95 \% \mathrm{Cl}: 0.36,0.78)$ cases compared to $34.8 \%(95 \% \mathrm{Cl}: 0.25,0.47)$ in erosion case. Higher positive rate of CagA antibody was significantly $(p=0.03)$ associated with the presence of ulcer. The mean optical density (OD) values for CagA antibody in ulcer and erosion cases were not significantly different $(p=0.89 ;$ Table- 1$)$. $H$. pylori stool antigen and IgA antibodies were positive in all (100\% in both) CagA antibody positive ulcer cases while the rates were significantly $(p<0.05)$ less among the CagA antibody negative cases (42.8\% and $28.6 \%$; Table-2). Among the CagA positive erosion cases, the stool antigen and serum IgA were positive in $66.7 \%$ and $70.8 \%$ cases respectively compared to $55.6 \%$ and $53.3 \%$ cases in CagA negative cases $(p>0.05, p>0.05)$. H. pylori stool antigen was present in significantly $(p=0.04)$ higher proportion of CagA antibody positive ulcer 
Table-1: H. pylori CagA antibody in ulcer and erosion cases

\begin{tabular}{lcccc}
\hline \multirow{2}{*}{ Hp positive case } & \multirow{2}{*}{ Number } & \multicolumn{3}{c}{ CagA IgG antibody } \\
\cline { 3 - 5 } & & Positive $\mathbf{n ~ ( \% ) ~}$ & $\mathbf{9 5 \%} \mathbf{C l}$ & Mean OD value \\
\hline Ulcer & 17 & $10(58.8)$ & $0.36,0.78$ & $1.91 \pm 0.35$ \\
Erosion & 69 & $24(34.8)$ & $0.25,0.47$ & $1.86 \pm 0.20$ \\
\hline Total & 86 & $34(39.5)$ & $0.30,0.50$ & $1.87 \pm 0.17$ \\
\hline
\end{tabular}

Note: $p=0.03$ by $Z$ test (one-tailed) compared between ulcer and erosion cases; $p=0.89$ by student's $t$ test Compared between mean antibody concentration of ulcer and erosion cases; $\mathrm{Hp}=$ Helicobacter pylori; $\mathrm{Cl}$ : Confidence Interval; OD: Optical Density

Table-2: Presence of $H$. pylori stool antigen, IgA and IgG antibodies in relation to CagA antibody status in ulcer and erosion cases

\begin{tabular}{|c|c|c|c|c|c|c|}
\hline \multirow{2}{*}{$\begin{array}{l}\text { Hp positive } \\
\text { Case }\end{array}$} & \multirow{2}{*}{$\begin{array}{c}\text { CagA antibody } \\
\text { status }\end{array}$} & \multirow{2}{*}{ Number } & \multicolumn{4}{|c|}{ Number (\%) positive for $\boldsymbol{H}$. pylori } \\
\hline & & & Stool Ag & $\lg A$ & IgG & RUT \\
\hline \multirow{3}{*}{$\begin{array}{l}\text { Ulcer } \\
(n=17)\end{array}$} & Anti-CagA positive & 10 & $10(100)$ & $10(100)$ & $10(100)$ & $10(100)$ \\
\hline & Anti-CagA negative & 07 & $03(42.8)$ & $02(28.6)$ & $07(100)$ & $3(42.8)$ \\
\hline & & & $p=0.01^{a}$ & $p=0.001^{a}$ & - & $p=0.01^{a}$ \\
\hline \multirow{4}{*}{$\begin{array}{l}\text { Erosion } \\
(n=69)\end{array}$} & Anti-CagA positive & 24 & $16(66.7)$ & $17(70.8)$ & $23(95.8)$ & $11(45.8)$ \\
\hline & Anti-CagA negative & 45 & $25(55.6)$ & $24(53.3)$ & $44(97.8)$ & $16(35.5)$ \\
\hline & & & $p=0.37^{b}$ & $p=0.16^{b}$ & $p=0.65^{b}$ & $p=0.41^{b}$ \\
\hline & & & $p=0.04^{c}$ & $p=0.06^{c}$ & $p=0.51^{c}$ & $p=0.003^{c}$ \\
\hline
\end{tabular}

Note: $p$ value was calculated by $Z$ test; $a=$ Compared between CagA positive and CagA negative ulcer cases for stool antigen, IgA, IgG and RUT; $b=$ Compared between CagA positive and CagA negative erosion cases for stool antigen, IgA, IgG and RUT; $c$ = Compared between CagA positive ulcer and erosion cases for stool antigen, IgA, IgG and RUT; Hp = Helicobacter pylori; RUT=Rapid Urease Test

cases compared to erosion cases (100\% vs. $66.7 \%)$. No significant difference was observed for $\lg A$ in CagA positive ulcer and erosion cases. Serum $H$. pylori IgG was present in almost equal proportion in both ulcer and erosion cases with and without positive CagA antibodies (Table-2).

\section{Discussion}

Prevalence studies have indicated that $H$. pylori infection is extremely common in Bangladesh as in other developing countries [8]. The reported seroprevalence of $H$. pylori in the hospitalized Bangladeshi population has been reported as $77.4 \%$ and CagA antibodies detected in $86 \%$ of those [9]. A high association of $H$. pylori with peptic ulcer (77\%) and gastritis (74\%) was observed [10].
In our previous study, we found that $83.5 \%$ of dyspeptic cases were positive for $H$. pylori infection either by stool antigen or serum anti-H. pylori IgA [11]. In the present study, we attempted to find out the anti-CagA IgG status in dyspeptic patients. We found that only $39.5 \%$ dyspeptic patients were CagA IgG positive although $58.8 \%$ ulcer patients were CagA IgG positive compared to $34.8 \%$ in erosion cases. However, a high prevalence of cagA positive strains (75\%) was reported in Bangladeshi patients with peptic ulcer diseases compared to strains from patients with non-ulcerated diseases (55\%) by PCR [12]. Another study analyzed cagA and vacA subtypes and their association with severe histology phenotypes among Bangladeshi population and found $73.2 \%$ of isolated $H$. pylori carried cagA. They also observed that patients who 
were infected with cagA positive strains had more severe histological scores than patients infected with cagA negative strains [13]. Also, an earlier study showed that persons carrying $\operatorname{cag} A$ positive strains had greater degrees of gastric inflammation and epithelial cell damage than those who had cagA negative strains [14]. Therefore, CagA antibody could be a good marker to identify patients with a risk of developing future complications. Infection with CagA-positive strains is associated with increased gastric cancer [15]. Low rate of CagA positivity observed in our study population could be due to the fact that we had more erosion cases than that of ulcer indicating milder form of disease. Frequency of CagA seropositivity has been variable in different countries: $50 \%$ in Turkey, $35.6 \%$ in Iran and $86.1 \%$ in Italy [16-18]. We also found that all CagA IgG positive ulcer cases were also positive for RUT, $H$. pylori stool antigen, $H$. pylori IgG and IgA antibodies.

The study has shown that in our population less CagA positive strain is associated with erosion than ulcer cases and further prospective study is necessary to find out its implication in disease process.

\section{Conflicts of interest}

The authors declare that there was no conflict of interests.

\section{Funding}

The study was funded by the grant from Ibrahim Medical College.

\section{References}

1. Dunn BE, Cohen H, Blaser MJ. Helicobacter pylori. Clin Microbiol Rev. 1997; 10: 720-741.

2. Blaser MJ. Intrastrain differences in Helicobacter pylori. A key question in mucosal damage? Ann Med. 1995; 27: 559-563.

3. Van Doorn LJ, Figueiredo C, Sanna R, Plaisier A, Schneeberger $\mathrm{P}$, de Boer $\mathrm{W}$, et al. Clinical relevance of the $\operatorname{cag} A, \operatorname{vac} A$, and ice $A$ status of Helicobacter pylori. Gastroenterology. 1998; 115: 58-66.
4. Kuipers EJ, Perez-Perez GI, Meuwissen SG, Blaser MJ. Helicobacter pylori and atrophic gastritis: importance of the cagA status. J Natl Cancer Inst. 1995; 87: 1777-1780.

5. Maeda S, Ogura K, Yoshida H, Kanai F, Ikenoue $\mathrm{T}$, Kato $\mathrm{N}$, et al. Major virulence factors, VacA and CagA are commonly positive in Helicobacter pylori isolates in Japan. Gut. 1998; 42: 338-343.

6. Yamaoka Y, Kita M, Kodama T, Sawai N, Kashima $\mathrm{K}$, Imanishi J. Induction of various cytokines and development of severe mucosal inflammation by cagA gene positive Helicobacter pylori strains. Gut. 1997; 41: 442-451.

7. Weel JF, van der Hulst RW, Gerrits Y, Roorda P, Feller $\mathrm{M}$, Dankert J, et al. The interrelationship between cytotoxin-associated gene $A$, vacuolating cytotoxin, and Helicobacter pylorirelated diseases. J Infect Dis. 1996; 173: 1171-1175.

8. Mahalanabis D, Rahman MM, Sarker SA, Bardhan PK, Hildebrand P, Beglinger C, et al. Helicobacter pylori infection in the young in Bangladesh: prevalence, socioeconomic and nutritional aspects. Int J Epidemiol. 1996; 25: 894-898.

9. Nessa, J, Chart H, Owen RJ, Drasar B. Human serum antibody response to Helicobacter pylori whole cell antigen in an institutionalized Bangladeshi population. J Appl Microbiol. 2001; 90: 68-72.

10. Haque $M$, Rahman KM, Khan AA, Hasan $M$, Miah MRA, Rahman $T$, et al. Isolation and characterization of Helicobacter pylori strains from peptic ulcer patients in Dhaka, Bangladesh. Indian J Gastroenterol. 1995; 14: 128-130.

11. Khatun S, Rahman F, Shadia K, Dutta IK, Hoq $\mathrm{MN}$, Akter $\mathrm{F}$, et al. Evaluation of rapid stool antigen test for the diagnosis of Helicobacter pylori infection in patients with dyspepsia. IMC J Med Sci. 2016; 10(2): 39-44.

12. Rahman M, Mukhopadhyay AK, Nahar S, Datta S, Ahmad MM, Sarker S, et al. DNA-level characterization of Helicobacter pylori strains from patients with overt disease and with benign infections in Bangladesh. J clin Microbiol. 2003; 41(5): 2008-2014. 
13. Aftab $H$, Miftahussurur $M$, Subsomwong $P$, Ahmed F, Khan AKA, Matsumoto T, et al. Two populations of less-virulent Helicobacter pylori genotypes in Bangladesh. PLOS ONE. 2017; 12(8): e0182947.

14. Peek RM Jr, Miller GG, Tham KT, Perez-Perez GI, Zhao X, Atherton JC, et al. Heightened inflammatory response and cytokine expression to cagA+ Helicobacter pylori strains. Lab Invest. 1995; 73: 760-770.

15. Huang JQ, Zheng GF, Sumanac K, Irvine EJ, Hunt $\mathrm{RH}$. Meta-analysis of the relationship between cagA seropositivity and gastric cancer. Gastroenterology. 2003; 125:1636-1644.

16. Nazime OY, Ahmet S, Ali K, likay S. Detection of $H$. pylori infection by ELISA and western blot techniques and evaluation of anti-CagA seropositivity in adult Turkisk dyspeptic patients. World Gastroenterol. 2006; 12(33): 5375-5378.

17. Bonyadi M, Babaloo Z, Fattahi E, Khoshbaten M, Abbasalizade F, Poozesh S. Detection of $H$. pylori infection and cagA strains seropositivity in adult dyspeptic patients in east Azerbaijan, northwest of Iran. Iran J Clin Infect Dis. 2010; 5(4): 228-230.

18. Orsini B, Ciancio G, Surrenti E, Macrí G, Biagini MR, Milani S, et al. Serologic detection of $\operatorname{cagA}$ positive Helicobacter pylori infection in a northern Italian population. Helicobacter. 1998; 3(1): 15-20. 